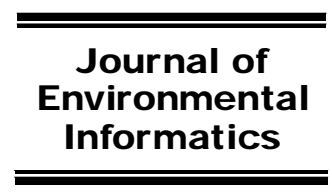

www.iseis.org/jei

\title{
A GIS-Based Integer Programming Approach for the Location of Solid Waste Collection Depots
}

\author{
W. Huang*, B. W. Baetz, and S. Razavi \\ Department of Civil Engineering, McMaster University, 1280 Main Street West, Hamilton ON L8S 4L8, Canada
}

Received 28 August 2015; revised 18 June 2016; accepted 18 June 2016; published online 25 September 2016

\begin{abstract}
This technical note uses an integer programming formulation and GIS tools to explore the feasibility of eliminating door-to-door solid waste collection in a community and replacing this municipal service with resident haulage of solid wastes to centralized depots. Obtained results show technical feasibility and considerable cost savings, which could be considered in the future by municipalities exploring options for their solid waste infrastructure systems.
\end{abstract}

Keywords: municipal solid waste, GIS, integer programming, waste collection, waste depot

\section{Introduction}

Municipal solid waste collection is an issue that every community has to deal with, and many citizens operate on a day-to-day basis without giving it much thought (Tan et al., 2015; Xu et al., 2014). Only when waste collection is disruptted do we see how important it is. For example, in 2009, the City of Toronto's worker strike caused a disruption in waste collection, which resulted in citizens dumping and piling up refuse around the city.

The current popular model of solid waste collection in North America is door-to-door garbage pickup. Residents place their wastes, compostables and recyclables in bags and bins on the curb, and a scheduled collection truck comes by, picks up the waste materials, and transports them to a materials recycling facility, composting facility, transfer station or directly to a landfill. A collection truck must drive to every household in the community, stop, pick up the wastes, drive to the next house, stop, pick up wastes, and so on. Stop-and-go driving consumes even larger amounts of fuel than driving without stops. Furthermore, suburban development patterns where houses are sprawled out and where houses sit on large properties results in longer distances being driven in order to collect every household's wastes.

This work looks at an alternate method to deal with waste disposal in North American municipalities by re-introducing the concept of taking one's own garbage to a centralized col-

\footnotetext{
* Corresponding author. Tel.: + 1306 5913508; fax: +1 9055299688. E-mail address: huangw23@mcmaster.ca (W. Huang).
}

ISSN: 1726-2135 print/1684-8799 online

(c) 2016 ISEIS All rights reserved. doi: 10.3808/jei.201600342 lection point. This change in policy could be prompted by operating budget constraints, where a cash-strapped municipallity in the future explores options for reducing municipal services. However, the collection points would not be the final disposal place for the materials. Rather, they would serve as a depot for waste collection trucks to pick up garbage without needing to stop at each door. Not only does this reduce collection truck driving distances, but it also makes people more accountable for their own garbage. This work aims to select the most optimal (or convenient) sites for depot placement by minimizing the distance which residents must travel in order to dispose of their wastes.

GIS and integer programming models were used in this study to determine potential site locations for such a depot system in the town of Dundas, Ontario, Canada. An integer programming model was applied to determine optimal and near-optimal locations for depots based on travel distance from households to depots.

GIS-based approaches have been applied in waste collection vehicle routing to improve the efficiency of traditionnal curbside pickup (Abdelli et al., 2016; Chang et al., 1997; Ghose et al., 2006; Louati, 2016; Tavares et al., 2009) common to many North American communities. These proposed models focused on the use of GIS to minimize travel distance, and consequently fuel costs, to bring wastes to a landfill.

GIS-assisted techniques have also been proposed for selecting waste disposal sites, transfer stations, and waste to energy facilities such as incineration and composting facilities (Eiselt et al., 2015; Sener et al., 2011; Shahabi et al., 2014; Sumathi et al., 2008; Tavares et al., 2011). Khan et al. (2016) developed a model for site selection and determining transportation costs for siting waste conversion facilities in a small community in Alberta, Canada. 
Karadimas et al. (2008) investigated the optimization of the placement of waste bins in a commercial-residential mixed area in Greece. The study area already used a waste bin system, and their study found that the number of bins could be reduced by $30 \%$. While this waste collection system is more centralized than curbside pickup, it still includes over 100 pickup points in a $0.5 \mathrm{~km}^{2}$ area. A similar analysis was performed for an Indian community by Vijay et al (2008), where they selected 46 locations for an area of $4 \mathrm{~km}^{2}$. Both of these studies contained many bin locations that still required complex vehicle routing to pick up wastes efficiently, while the research reported in this technical note implements a much smaller number of bin locations for a comparably sized area.

A previous study looked at the sizing and placement of material recycling depots based on GIS models (Valeo et al., 1998), with residents transporting the recyclable portion of their wastes to depots. This previous study used radial distances, which can be significantly different than the actual transport distances. The work presented in this technical note improves upon the Valeo et al. work by incorporating actual travel distances, and also looks at the full solid waste stream generated by households (recyclables, compostables and residual waste that is not recyclable or compostable and would require landfilling) under a projected future scenario of no individual household waste collection.

In this study, GIS software is used to determine potential waste depot locations, calculate the actual road distances between potential depots and the waste-generating sub-communities, and to illustrate graphically the obtained optimal depot location and utilization results.

\section{Methodology}

Integer programming was used as a tool to assist in the decision-making process to determine the optimal locations to site a number of waste bins across a range of potential depot locations (Ben-Awuah et al., 2015). GIS software was used to determine these potential locations for waste management depots (Blanchard et al., 2015). Potential sites were selected based on land-use type and proximity to sensitive areas, such as schools. Commercial sites may be desirable because they are typically high-traffic and encourage trip chaining (a person can dispose of their wastes while on their way to a store, for example). Public green spaces may be selected because they are city-owned, and encouraging more people to come and go from these areas can enhance the safety of the area. Frequent collection would be needed to prevent the depot area from becoming odorous. Bins would need to be designed with tight-closing covers to keep out scavenging wildlife.

For the purposes of this study, travel distances along roads will be used, as all potential users were assumed to drive or cycle along roads. Road-travel distances between the community points and each potential depot point were determined using the distance-measuring function in ArcMap 10, and MS Excel was used to perform the optimization with the data obtained from ArcMap. Integer programming methods were applied to select depot sites that minimize the travel distance of the community as a whole, given a set number of subcommunities.

Each variable $i$ represents a depot location, $j$ represents a subsection of the community, and $d_{i j}$ represents the distance between depot point $i$ and subcommunity $j . y_{i}$ is an integer variable representing whether or not a depot will exist at location $i$, and $x_{i j}$ indicates whether or not residents of subcommunity j drop their wastes off at depot location $i$.

The objective function for this problem is the following:

(1) The objective function minimizes, across all sub-communities, the actual distances travelled by road by citizens self-hauling wastes from their sub-community to potential depot locations:

$\operatorname{Min} Z=\sum_{i=1}^{I} \sum_{j=1}^{J} x_{i j} d_{i j}$

subject to the following constraints:

(2) Each sub-community is assigned to a depot, so that solid wastes are managed for the entire community:

$\sum_{i=1}^{I} x_{i j}=1$, for all $J$

(3) A depot must be present at the location in order for it to receive waste from any of the sub-communities:

$N y_{i}-\sum_{j=1}^{J} x_{i j} \geq 0$, for all $I$

where $N$ is the number of sub-communities in the community.

(4) The total number of depots equals a decision-maker defined value $(\mathrm{T})$ :

$\sum_{i=1}^{I} y_{i}=T$

where $\mathrm{T}$ is the total number of depot sites needed for the community.

(5) Technical constraints - Both the depot siting at a particular location and the use of a potential depot by a certain sub-community are modelled as integer variables.

$$
\begin{aligned}
& y_{i} \in \text { binary } \\
& x_{i j} \in \text { binary }
\end{aligned}
$$

\section{Case Study}

This methodology was applied to the community of Dundas, Ontario. Dundas is a community consisting of North Dundas (Olde Dundas) and South Dundas, with a combined population of approximately 25,000 people or 8,000 households (Statistics Canada, 2015). The community is divided down the middle by a major arterial road running east to west. 


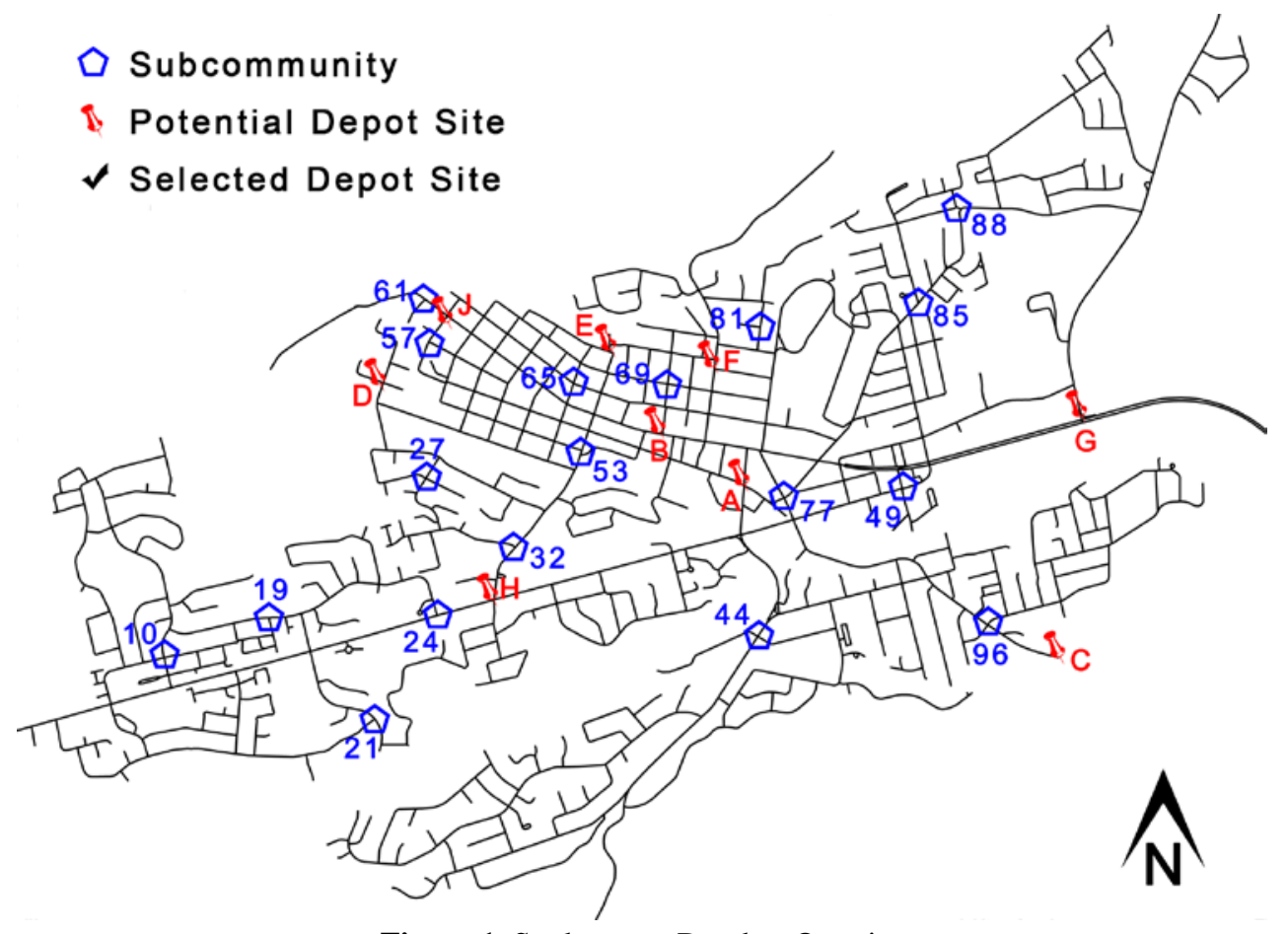

Figure 1. Study area - Dundas, Ontario.

The northern half has a grid-like configuration while the southern half has a more sprawling suburban pattern. Weekly waste collection is currently provided by the City of Hamilton, of which the community of Dundas is an electoral ward within the overall city. Recyclables are picked up by a private firm operating under contract to the City, and compostables and residual garbage are picked up by a split-volume collection truck owned and operated by the City of Hamilton.

Figure 1 shows the study area with potential depot sites (letters) and sub-communities (numbers). Due to the software limitations of Microsoft Excel's Solver add-in, a total of 5 potential depot sites and 40 sub-communities were selected. All depot sites are located either in a commercial parking lot or adjacent to public green spaces. Sub-communities were selected based on representative points. For example, most of the Pleasant Valley area in the south will always follow the same path to leave the area-by following the arterial road eastwards. Thus, point \#44 is a point that the entire community will pass through and is used to represent that sub-community.

For the purposes of this study, population distribution was not considered. It will be assumed that all sub-communities have an equal number of households, and thus their distance travelled will each be weighted the same. Realistically, slight variations in population density within the larger community may sway the decision to place depots closer to higher density areas. However, since Dundas is a mostly single-family residential town, the population densities are assumed to be reasonably equal.

\section{Results}

Figures 2 through 4 show the results for having either, 1 , 2 , or 3 centralized waste collection depots. As seen in these figures, when only one depot is allowed, it is developed in a more centralized location. When 3 depots are allowed, they are spread out to be closer to clusters of sub-communities. Eight thousand households are assumed to be evenly distributed among the selected sub-community points, thus there are 420 households per sub-community.

The average amount of waste generated annually by Canadians is $777 \mathrm{~kg}$ per capita (Wang, 2015), or $15 \mathrm{~kg}$ per week, assuming no waste diversion. With a population of approximately 25,000 people, the waste generation is approximately $375,000 \mathrm{~kg}$ per week. Assuming a bulk density of $160 \mathrm{~kg}$ per cubic meter, the total weekly volume of wastes is 2343 cubic meters of waste. If a $50 \%$ diversion rate by volume is assumed, this would result in 1172 cubic meters of waste. Thus, if three depots are placed in the community and emptied weekly, they would need to have a capacity of approximately $400 \mathrm{cu}-$ bic metres. Assuming bins with 40 cubic meter capacities are used, this would require 10 bins for each depot location. Thus, there would need to be more bins in more locations, more bins per location, or more frequent collection. However, one must note that solid wastes can become odorous very quickly, especially in warmer months, and more frequent collection may be beneficial for several purposes: reduction of odour and potential to attract vermin and wildlife, smaller and less noticeable bin sizes, less likelihood of overflowing, and less likelihood for vandalism. The three depot option may be the preferred al- 


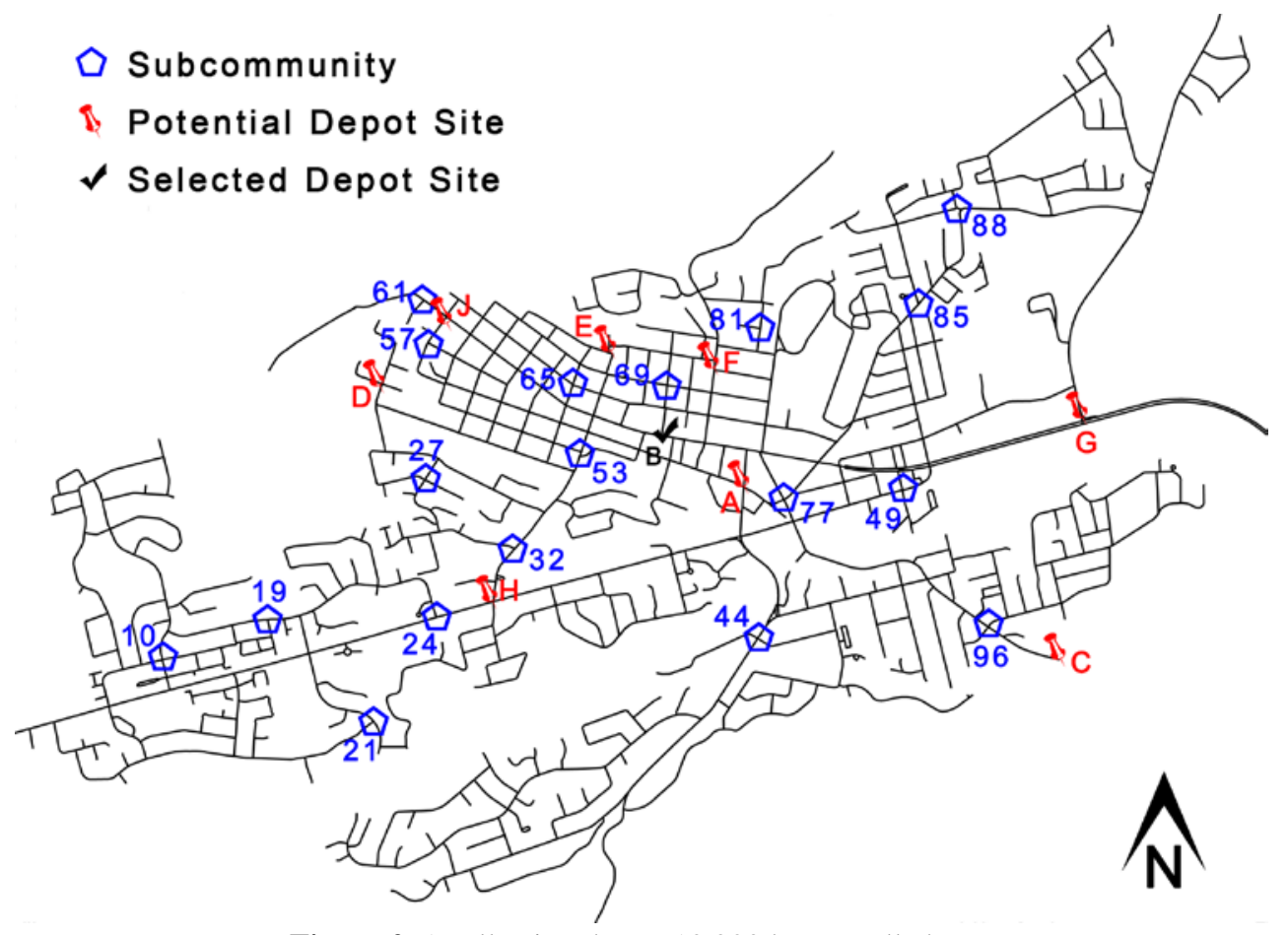

Figure 2. 1 collection depot: 10,080 km travelled.

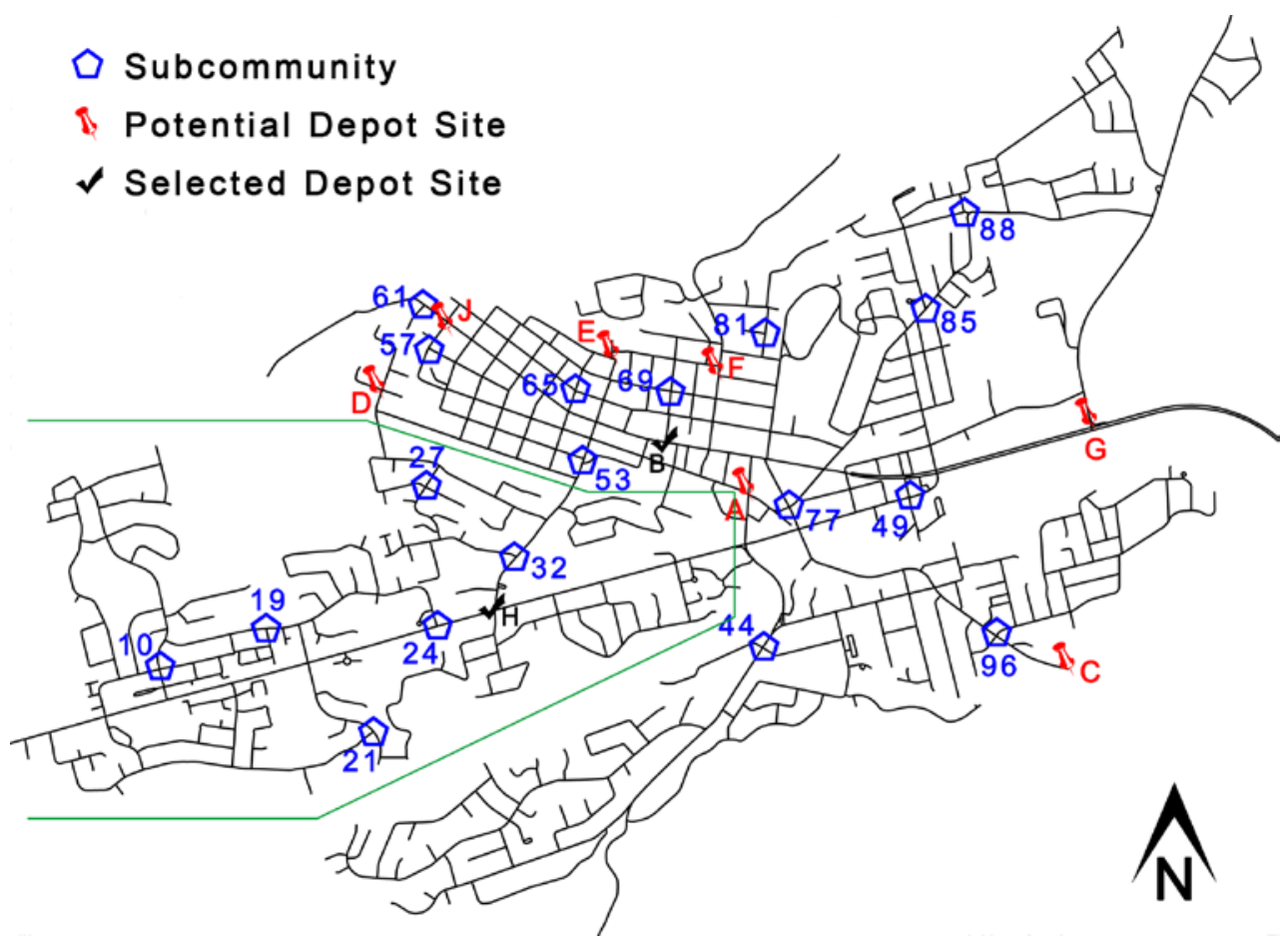

Figure 3. 2 collection depots: 8,148 km travelled.

ternative, as haul distances are substantially reduced and the number of bins at each depot would be significantly smaller.

The approximate cost for municipal door-to-door waste collection ranges from \$150 200 per household (Kelleher et al., 2005). Dundas has approximately 8,000 households so fo- llowing this assumption, the cost for waste collection come to $\$ 1.2 \sim 1.6$ million annually. These costs assume weekly curbside pickup.

In either a curbside scenario or a waste depot scenario, wastes will still have to be transported downstream to waste 


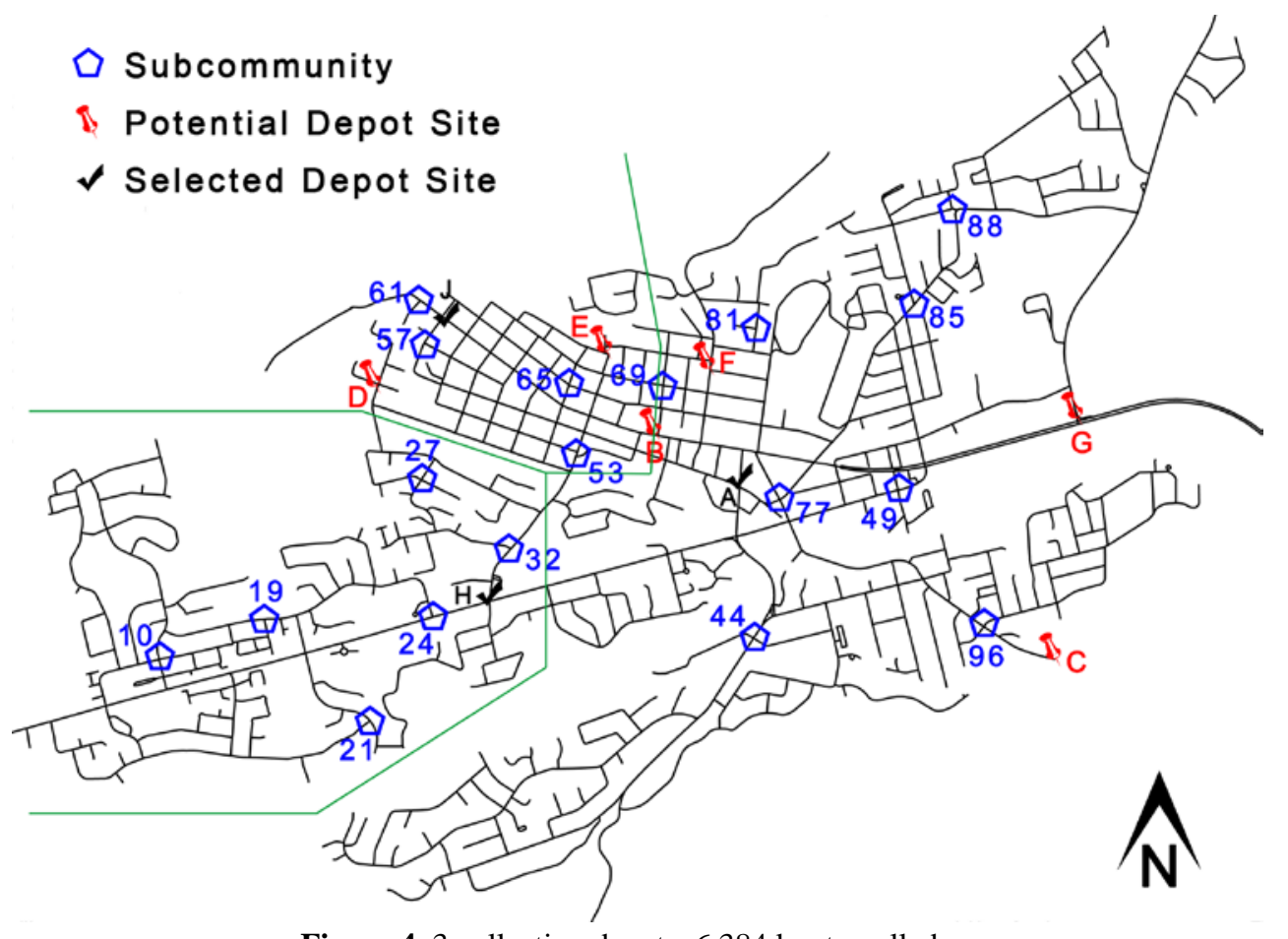

Figure 4. 3 collection depots: 6,384 km travelled.

management facilities (such as recycling facilities, composting facilities, landfill). The depot scenario would shift the burden to the individual household to a large degree, and for a community population of 25,000 people this may realize an annual cost savings in excess of a million dollars. Actual cost savings would require a detailed evaluation of current doorto-door collection costs, and the costs associated with haulage of waste materials by municipal vehicles from the centralized collection depots to downstream waste management facilities (similar to the costing methodology employed by Mora et al., 2014).

\section{Conclusions}

This work proposes an alternative method for the collection of municipal solid waste. The current door-to-door curbside collection system is energy and cost-intensive and unsustainable, and it is important to consider alternative methods. This work proposes the idea of waste dropoff depots in urban communities, and have members of the community bring their waste materials to depots located within the community. This work provides an integer programming optimization method for selecting optimal locations, using GIS to select potential sites and measure actual travel distances and Excel's Solver tool to perform the optimization to determine the best depot locations based on minimizing cumulative resident-haulage distances.

Acknowledgments. This research has been supported by the Natural Sciences and Engineering Research Council of Canada and the Department of Civil Engineering, McMaster University.

\section{References}

Abdelli, I.S., Abdelmalek, F., Djelloul, A., Mesghouni, K., and Addou, A. (2016). GIS-based approach for optimised collection of household waste in Mostaganem city (Western Algeria). Waste Manage. Res., 34(5), 417-426. http://dx.doi.org/10.1177/0734242 X16633519

Ben-Awuah, E., Elkington, T., Askari-Nasab, H., and Blanchfield, F. (2015). Simultaneous production scheduling and waste management optimization for an oil sands application. J. Environ. Inf., 26(1), 80-90. http://dx.doi.org/10.3808/jei.201500305

Blanchard, S.D., Pontius, R.G., and Urban, K.M. (2015). Implications of using $2 \mathrm{~m}$ versus $30 \mathrm{~m}$ spatial resolution data for suburban residential land change modeling. J. Environ. Inf., 25(1), 1-13. http://dx.doi.org/10.3808/jei.201400284

Chalkias, C., and Lasaridi, K. (2009). A GIS based model for the optimisation of municipal solid waste collection: the case study of Nikea, Athens, Greece. Wseas Trans. Environ. Dev., 10(5), 640650.

Chang, N.B., Lu, H.Y., and Wei, Y.L. (1997). GIS technology for vehicle routing and scheduling in solid waste collection systems. $J$. Environ. Eng., 123(9), 901-910. http://dx.doi.org/10.1061/(ASCE) 0733-9372(1997)123:9(901)

Eiselt, H.A., and Marianov, V. (2015). Location modeling for municipal solid waste facilities. Comput. Oper. Res., 62, 305-315. http://dx.doi.org/10.1016/j.cor.2014.05.003

Ghose, M.K., Dikshit, A.K., and Sharma, S.K. (2006). A GIS based transportation model for solid waste disposal-A case study on Asansol municipality. Waste Manage., 26(11), 1287-1293. http:// dx.doi.org/10.1016/j.wasman.2005.09.022

Karadimas, N.V., and Loumos, V.G. (2008). GIS-based model- ling for the estimation of municipal solid waste generation and collection. Waste Manage. Res., 26(4), 337-346. http://dx.doi. org/10.1177/0734242X07081484 
Kelleher, M., Robins, J., and Dixie, J. (2005). Taking out the trash: how to allocate costs fairly, C.D. Howe Institute.

Khan, M.M.U.H., Jain, S., Vaezi, M., and Kumar, A. (2016). Development of a decision model for the techno-economic assessment of municipal solid waste utilization pathways. Waste Manage., 48, 548-564. http://dx.doi.org/10.1016/j.was man.2015.10.016

Liebman, J.C., Wathne, M., and Male, J.W. (1975). Minimum cost in residential refuse vehicle routes. J. Environ. Eng. Div., 101(3), 399-412.

Louati, A. (2016). Modeling municipal solid waste collection: A generalized vehicle routing model with multiple transfer stations, gather sites and inhomogeneous vehicles in time windows. Waste Manage., 52, 34-49. http://dx.doi.org/10.1016/j.wasman.2016.03. 041

Mora, C., Manzini, R., Gamberi, M., and Cascini, A. (2014). Environmental and economic assessment for the optimal configuration of a sustainable solid waste collection system: a 'kerbside'case study. Prod. Plann. Control, 25(9), 737-761. http://dx.doi.org/10. 1080/09537287.2012.750386

Şener, Ş., Sener, E., and Karagüzel, R. (2011). Solid waste dispo- sal site selection with GIS and AHP methodology: a case study in Senirkent-Uluborlu (Isparta) Basin, Turkey. Environ. Monit. Assess., 173(1-4), 533-554. http://dx.doi.org/10.1007/s10661-0101403-X

Shahabi, H., Keihanfard, S., Ahmad, B.B., and Amiri, M.J.T. (2014) Evaluating Boolean, AHP and WLC methods for the selection of waste landfill sites using GIS and satellite images. Environ. Earth Sci., 71(9), 4221-4233. http://dx.doi.org/10.1007/s12665-013-28 $16-\mathrm{y}$
Sumathi, V.R., Natesan, U., and Sarkar, C. (2008). GIS-based approach for optimized siting of municipal solid waste landfill. Waste manage., 28(11), 2146-2160. http://dx.doi.org/10.1016/j. wasman.2007.09.032

Tan, Q, Huang, G.H., and Cai, Y.P. (2015). A fuzzy evacuation management model oriented toward the mitigation of emissions. $J$. Environ. Inf., 25(2), 117-125. http://dx.doi.org/10.3808/jei.201400 272

Tavares, G., Zsigraiová, Z., and Semiao, V. (2011). Multi-criteria GIS-based siting of an incineration plant for municipal solid waste. Waste Manage., 31(9), 1960-1972. http://dx.doi.org/10.1016/j. wasman.2011.04.013

Tavares, G., Zsigraiova, Z., Semiao, V., and Carvalho, M.D.G. (2009). Optimisation of MSW collection routes for minimum fuel consumption using 3D GIS modelling. Waste Manage., 29(3), 1176-1185. http://dx.doi.org/10.1016/j.wasman.2008.07.013

Valeo, C., Baetz, B.W., and Tsanis, I.K. (1998). Location of Recycling Depots with GIS. J. Urban Plann. Dev., 124(2), 93-99. http://dx.doi.org/10.1061/(ASCE)0733-9488(1998)124:2(93)

Vijay, R., Gautam, A., Kalamdhad, A., Gupta, A., and Devotta, S. (2008). GIS-based locational analysis of collection bins in municipal solid waste management systems. J. Environ. Eng. Sci., 7(1), 39-43. http://dx.doi.org/10.1139/S07-033

Wang, J (2015). Human Activity and the Environment (16-201-X), Statistics Canada.

Xu, Y., Huang, G.H., Cheng, G.H., Liu, Y., and Li, Y.F. (2014). A two-stage fuzzy chance-constrained model for solid waste allocation planning. J. Environ. Inf., 24(2), 101-110. http://dx.doi. org/10.3808/jei.201400261 